\title{
Health Effects of Mobile Tower Radiation on Human - Case Study
}

\author{
Lalrinthara Pachuau*, Zaithanzauva Pachuau \\ Dept. of Physics, Mizoram University, Tanhril, India. \\ * Corresponding author. Tel.: +91-9862358768; email: rinapachuau@yahoo.com \\ Manuscript submitted November 4, 2015; accepted March 16, 2016. \\ doi: 10.17706/ijapm.2016.6.2. 72-79
}

\begin{abstract}
In the present paper, we presented the study of complaints on thirteen (13) different health symptoms faced by inhabitants living near mobile tower - Global System for Mobile Communication (GSM $900 \& 1800$ ) and those inhabitants living in the area where there is no mobile tower. The study was conducted in fourteen different localities in Aizawl city and four different localities outside Aizawl city in the year 2014 \& 2015. Questionnaires were conducted in all the localities. Power densities were measured in different places in all the localities. Health complaints between the localities were compared with that of the locality where there is no mobile tower. It was found that power density is much higher in the area where there is mobile tower than the area where there is no mobile tower. Questionnaire responses from all the localities were statistically analysed and compared by performing t-test. Out of the thirteen (13) different symptoms studied it was found that the comparisons are statistically significant with $\mathrm{p}<0.05$ in six symptoms. Significant Health complaints start to occur when average power density of the locality is more than $2.145 \mathrm{~mW} / \mathrm{m}^{2}$. Women were statistically more affected $(\mathrm{p}<0.05)$ than male. It was found that there was strong positive correlation between power density and health complaints with $\mathrm{R}^{2}$ value 0.853 .
\end{abstract}

Key words: Health symptoms, power density, RF radiation.

\section{Introduction}

The introduction in the 1990s of mobile phone using the digital Global System for Mobile Communication (GSM) bandwidths 900 and 1800 megahertz (MHz) and the subsequent introduction of the Universal Mobile Telecommunications System (UMTS) have led to widespread use of this technology. This development has raised public concerns and substantial controversy about the potential health effects of the radiofrequency electromagnetic field emissions of this technology [1]. It is believed that mobile phones produce RF energy of non-ionizing radiation which is too low to heat the body's tissues, and hence is unlikely to have the same impact on human health as those produced by ionizing radiations such as X-rays [2]. A small portion of the population attributes non specific symptoms of ill health, such as sleep disturbance, headache, fatigue etc. Ref. [3] to exposure to electromagnetic fields. This phenomenon is described as electromagnetic hypersensitivity or 'idiopathic environmental intolerance with attribution to electromagnetic fields [4]. Additionally, individuals who are hypersensitive to electromagnetic fields often claim to be able to perceive radiofrequency electromagnetic fields in their daily life [5]. With the significant increase in mobile phone usage, possible health risks related to RF exposure have become the subject of considerable attention [6].

People are generally exposed to mobile tower radiation under far-fields conditions, i.e. radiation from a 
source located at distance more than one wavelength. Mobile tower radiation exposure can occur continuously but the levels are considerably lower than the local maximum level that occur when someone uses a mobile phone handset [7]. A recent study that measures personal exposure to radiofrequency electromagnetic fields in a swiss population sample demonstrated that the average exposure contribution from mobile tower is relevant for cumulative long term whole body exposure to radiofrequency electromagnetic fields. However, as expected, it is of minor importance for cumulative exposure to the head of regular mobile phone users [8].

In 2005, the World Health Organisation (WHO) organized a workshop on exposure to mobile tower radiation and its health consequences and subsequently published a paper summarizing the state of knowledge on the matter [9]. At that time, studies about the health impacts of mobile tower radiation were scarce and of low quality because most of the previous research on the health effects of radiofrequency electromagnetic fields had focused on exposure to mobile phone handsets and on effects related to head exposure, such as brain tumours or changes in brain physiology. Later, research efforts have increased in response to public complaints describing decreased well-being associated with mobile tower radiation [10].

Many studies address the impact of mobile phone radiations on human body, only a few consider the effect of human exposure to base stations although such an effect may be greater as more body parts can absorb RF energy [11]. Over the last decade, there has been a great deal of concern about possible health consequences caused by human exposure to RF in general and radiations from base stations in particular [6]. This includes effect from exposure to both cell phones and base stations. Health concerns can be divided into two main categories : short term and long term effects. The short term effect includes brain electrical activity, cognitive function, sleep, heart rate and blood pressure [12]. However, the long term effects includes tinnitus, headache, dizziness, fatigue, sensations of warmth, dysesthesia of the scalp, visual symptoms, memory loss and sleep disturbance, muscle problem and epidemicological effects including cancer and brain tumours [13].

In May 2011, International Agency for Research on Cancer (IARC) has classified RF field as possibly carcinogenic to human (group 2B) based on increased risk for glioma, a malignant type of brain cancer associated with wireless phone use [14].

\section{Methodology}

\subsection{Questionnaire}

To study the health hazards and problems faced by the inhabitants living close to the base station, questionnaire survey was conducted on 13 different symptoms in different localities of Aizawl. The questionnaire was similar to that developed for the study on mobile phone users by Santini et al. [15]. One of the localities where the survey was done was called Lawipu which is situated in the outskirt of Aizawl. In Lawipu there is no mobile phone tower, the nearest tower is located in Maubawk which is about $1 \mathrm{~km}$ away. Hence, the questionnaire responses from Lawipu was used as the reference for comparing with all other localities as the power density was so low compared to different international standards. The level of complaints for the studied symptoms was expressed by using a scale of : $0=$ never, $1=$ sometimes, $2=$ often, $3=$ very often.

\subsection{Power Density}

The amount of energy passing through unit area per unit time is called Power density $\left(\mathrm{P}_{\mathrm{d}}\right)$. If the transmitter is isotropic, it radiates energy uniformly in all directions. The power of a transmitter that is radiated from an isotropic antenna will have a uniform power density in all directions. The surface area increases by the square of the radius, therefore power density decreases by the square of the radius. 
Power density form an isotropic antenna is given by

$$
P_{d}=\frac{P_{t}}{4 \pi R^{2}}
$$

where $P_{t}=$ Transmitter power (peak or average depending on how Pd is to be specified), $\mathrm{R}=$ radius of the sphere.

If $G$ be gain of the antenna which is the ratio of power radiated in the desired direction as compared to the power radiated from the antenna, and let $\mathrm{n}$ be the number of transmitter, we have [16]

$$
P_{d}=\frac{n P_{t} G}{4 \pi R^{2}}
$$

If the antenna gain is given in $\mathrm{dB}$ rather than dimensionless number, it can be convert back to dimensionless number by using the formula

$$
G=[10]^{\left(\frac{x}{10}\right)}
$$

where $x$ is the antenna gain given in $\mathrm{dB}, \mathrm{G}$ is the antenna gain expressed in dimensionless number.

Power density measurement was carried out at different places in each locality using Spectran HF-60105 V4, manufactured by Aaronia, Germany. Power density and questionnaire response from Lawipu was taken as reference for comparison with that of others. The main purpose of the measurement was to find whether there is correlation between the health complaints and the measured power densities. Average value of the measured power densities of each location was compared the number of significant health complaints (with $p<0.05)$. The bivariate correlation graphs were plotted.

\subsection{Frequency Spectrum}

Frequency spectrum of the radiation had been recorded in each locality. The same instrument HF-60105V4, manufactured by Aaronia, Germany was used to analyse the frequency spectrum. The instrument is capable of measuring non-ionizing radiation for frequency range of $1 \mathrm{MHz}$ to $9.4 \mathrm{GHz}$.

\section{Results and Discussions}

\subsection{Questionnaire Analysis}

Analysis of the questionnaire from all the participants is given in Table 1 and Table 2. Only those localities with significant health symptoms are given in the tables. T-test analysis was performed for the comparison of health complaints. Scale numbers 2 and 3 are given more considerations as they are positive responses. Table 1 shows comparison of questionnaire responses between that of Lawipu inhabitants and of inhabitants of other localities. Those inhabitants living near base stations in other localities are having more health complaints than those in Lawipu who are exposed to very weak RF Radiation. In table 2, comparisons of health complaints between male and female in other localities are given. From each locality fifty (50) individuals participated, 24 males and 26 females, and in Lawipu the same number 24 males and 26 females participated in the questionnaire.

When questionnaire analysis were done with t-test it has been observed that the health complaints are significant ( $p<0.05$, where $\mathrm{p}$ is significant level) in ten (10) different health symptoms in at least one of the scales 2 or 3 or both (Table 1). Muscle pain is the most common complaint, it is significant on both scales 2 
and 3 in ten (10) different localities out of the 17 different localities which were compared with Lawipu. All the localities are in Aizawl city where mobile towers had been erected for at least the last five years.

Table 1. t-Test Analysis Showing Significant Health Complaints on Scales 2 and 3 on Comparison of Responses from Lawipu with Other Localities. * Mark Indicates Significance with $p<0.05$.

\begin{tabular}{|c|c|c|c|c|c|c|c|c|c|c|c|c|c|c|c|c|c|c|c|c|c|c|c|c|c|c|c|}
\hline \multirow{3}{*}{$\begin{array}{c}\mathrm{Sl} \\
\text { No. }\end{array}$} & \multirow[t]{2}{*}{ Symptoms } & \multicolumn{2}{|c|}{1} & \multicolumn{2}{|c|}{2} & \multicolumn{2}{|c|}{3} & \multicolumn{2}{|c|}{4} & \multicolumn{2}{|c|}{5} & \multicolumn{2}{|c|}{6} & 7 & & \multicolumn{2}{|l|}{8} & \multicolumn{2}{|c|}{9} & \multicolumn{2}{|c|}{10} & \multicolumn{2}{|c|}{11} & \multicolumn{2}{|c|}{12} & \multicolumn{2}{|c|}{13} \\
\hline & & $\begin{array}{l}\text { 亗 } \\
\text { 总 }\end{array}$ & & 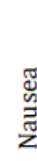 & & षे & 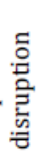 & 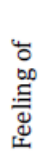 & & 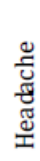 & & ह్ & & 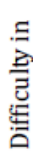 & 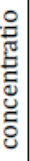 & 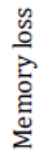 & & 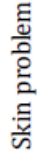 & & $\stackrel{\bar{w}}{\frac{w}{5}}$ & 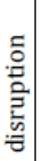 & 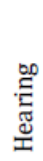 & & 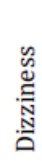 & & 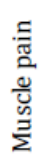 & \\
\hline & Scale & 2 & 3 & 2 & 3 & 2 & 3 & 2 & 3 & 2 & 3 & 2 & 3 & 2 & 3 & 2 & 3 & 2 & 3 & 2 & 3 & 2 & 3 & 2 & 3 & 2 & 3 \\
\hline 1 & Lawipu & - & - & - & - & - & - & - & - & - & - & - & - & - & - & - & - & - & - & - & - & - & - & - & - & - & - \\
\hline 2 & K.Vengthlang & & & & & & & & & & & & & & & & & & & & & & & & & * & * \\
\hline 3 & A.Veng & & & & & & & & & * & * & & & & & & & & & & & & & & & * & \begin{tabular}{|l|l}
$*$ \\
\end{tabular} \\
\hline 4 & Tanhril & $*$ & & & & & & & & * & & & & & & & & & & & & & & 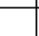 & & * & * \\
\hline 5 & Chanmari & & & & & & & & & * & & & & & & & & & & & & & & * & & * & * \\
\hline 6 & Zemabawk & $*$ & * & & & * & * & & & & & & & & & & & & & & & & & * & * & * & * \\
\hline 7 & M.Vengthlang & $*$ & & & & & & & & * & * & & & & & & & & & & & & & & & & \\
\hline 8 & Maubawk & & & & & * & & & & & & & * & & & & & & & & & & & & & * & * \\
\hline 9 & Ramhlun N & * & & & & * & & & & & & & * & & & & & & & & & & & * & & * & * \\
\hline 10 & B.Vengthlang & & & & & * & & & & $*$ & * & * & & & & & & & & & & & & & & * & * \\
\hline 11 & C.Veng & * & & & & * & & & & & & * & & * & & * & & & * & * & & & & * & & * & * \\
\hline
\end{tabular}

Table 2. t-Test Analysis Showing Significant Health Complaints on Scales 2 and 3 on Comparison of Responses between Male and Female from Each of the Localities. * Mark Indicates Significance with $p<$ 0.05 .

\begin{tabular}{|c|c|c|c|c|c|c|c|c|c|c|c|c|c|c|c|c|c|c|c|c|c|c|c|c|c|c|c|}
\hline \multirow{3}{*}{$\begin{array}{c}\text { Sl } \\
\text { No. }\end{array}$} & \multirow[t]{2}{*}{ Symptoms } & \multicolumn{2}{|c|}{1} & \multicolumn{2}{|c|}{2} & \multicolumn{2}{|c|}{3} & \multicolumn{2}{|c|}{4} & \multicolumn{2}{|c|}{5} & \multicolumn{2}{|c|}{6} & \multicolumn{2}{|c|}{7} & \multicolumn{2}{|c|}{8} & \multicolumn{2}{|c|}{9} & \multicolumn{2}{|c|}{10} & \multicolumn{2}{|c|}{11} & \multicolumn{2}{|c|}{12} & \multicolumn{2}{|c|}{13} \\
\hline & & \multicolumn{2}{|c|}{ 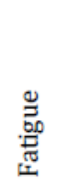 } & \multicolumn{2}{|c|}{ 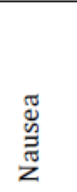 } & \multicolumn{2}{|c|}{ 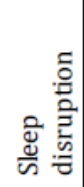 } & \multicolumn{2}{|c|}{ 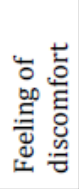 } & \multicolumn{2}{|c|}{ 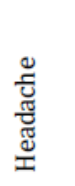 } & \multicolumn{2}{|c|}{ छี } & \multicolumn{2}{|c|}{ 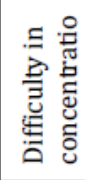 } & \multicolumn{2}{|c|}{$\begin{array}{l}\mathscr{0} \\
\stackrel{0}{2} \\
\stackrel{0}{0} \\
\sum\end{array}$} & \multicolumn{2}{|c|}{ 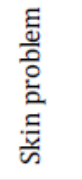 } & \multicolumn{2}{|c|}{ 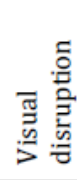 } & \multicolumn{2}{|c|}{ 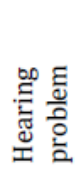 } & \multicolumn{2}{|l|}{$\begin{array}{l}\mathscr{d} \\
\stackrel{\mathbb{N}}{*}\end{array}$} & \multicolumn{2}{|c|}{ 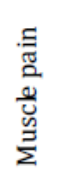 } \\
\hline & Scale & 2 & 3 & 2 & 3 & 2 & 3 & 2 & 3 & 2 & 3 & 2 & 3 & 2 & 3 & 2 & 3 & 2 & 3 & 2 & 3 & 2 & 3 & 2 & 3 & 2 & 3 \\
\hline 1 & Lawipu & - & - & - & - & - & - & - & - & - & - & - & - & - & - & - & - & - & - & - & - & - & - & - & - & - & - \\
\hline 2 & A.Veng & & & & & & & & & * & & & & & & & & & & & & & & & & * & * \\
\hline 3 & Tanhril & & & & & & & & & & $*$ & & & & & & & & & & & & & & & * & $*$ \\
\hline 4 & Chanmari & & & & & & & & & & & & & & & & & & & & & & & & & * & * \\
\hline 5 & Zemabawk & * & & & & & & & & * & & & & & & & & & & & & & & & & & \\
\hline 6 & M.Vengthlang & * & & & & & & & & * & & & & & & & & & & & & & & & & & \\
\hline 7 & Maubawk & & & & & & & & & * & * & & & & & & & & & & & & & & & $*$ & $*$ \\
\hline 8 & Ramhlun N & & & & & & & & & & & & & & & & & & & & & & & & & * & * \\
\hline 9 & B.Vengthlang & * & & & & * & & & & * & & & & & & & & & & & & & & & & * & * \\
\hline 10 & C.Veng & & & & & $*$ & & & & & & $*$ & & & & & & & & & & & & $*$ & * & * & * \\
\hline
\end{tabular}

Comparison between responses on health complaints of male and female is given in table 2 . It has been found that out of the 17 different localities at least one significant health complaint was observed in ten (10) localities which were all in Aizawl city. Out of the thirteen different symptoms studied, significant health complaints were found in six (6) symptoms, females being more affected.

\subsection{Power Density Measurement}

Power density of RF radiation was measured at different places randomly in each locality. The measured average values of each locality was compared with that of Lawipu and different standards like ICNIRP, Indian standard, Bioinitiative report and Salzburg resolution 2001. Many of the measured values are higher than that of the safe limits recommended by Bioinitive Report $2012\left(0.5 \mathrm{~mW} / \mathrm{m}^{2}\right)$ [17], Salzburg resolution $2000\left(1 \mathrm{~mW} / \mathrm{m}^{2}\right)$ [18], EU (STOA) $2001\left(0.1 \mathrm{~mW} / \mathrm{m}^{2}\right)$ [18]. However, all the measured values were well below the current ICNIRP safe level $\left(4700 \mathrm{~mW} / \mathrm{m}^{2}\right)$ [18] and the current Indian Standard $\left(450 \mathrm{~mW} / \mathrm{m}^{2}\right)$ [18]. In Lawipu, where there are no mobile tower, the average value of power density of GSM 900 and GSM 1800 was $0.042 \mathrm{~mW} / \mathrm{m}^{2}$ which was well below Bioinitive Report $2012\left(0.5 \mathrm{~mW} / \mathrm{m}^{2}\right)$ [17], Salzburg resolution $2000\left(1 \mathrm{~mW} / \mathrm{m}^{2}\right)$ [18], EU (STOA) $2001\left(0.1 \mathrm{~mW} / \mathrm{m}^{2}\right)$ [17], the current ICNIRP safe level $\left(4700 \mathrm{~mW} / \mathrm{m}^{2}\right)$ [18] 
and the current Indian Standard $\left(450 \mathrm{~mW} / \mathrm{m}^{2}\right)$ [19]. Measurement of power density in different localities are given in Table 3 .

Table 3. Measurement of Power Densities in the Studied Localities

\begin{tabular}{|c|c|c|c|c|c|c|c|c|c|c|}
\hline \multirow{2}{*}{$\begin{array}{l}\text { S1. } \\
\text { No. }\end{array}$} & \multirow{2}{*}{ Locality } & \multirow[b]{2}{*}{ 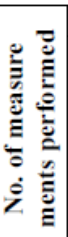 } & \multicolumn{2}{|c|}{ Average power density } & \multirow[b]{2}{*}{$\begin{array}{c}\text { Average } \\
\text { value of } \\
\text { GSM } 900 \\
\& 1800 \\
\left(\mathrm{mWV} / \mathrm{m}^{2}\right)\end{array}$} & \multirow[b]{2}{*}{ 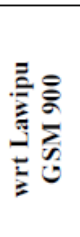 } & \multirow[b]{2}{*}{ 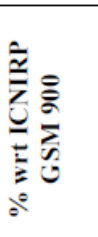 } & \multirow[b]{2}{*}{ 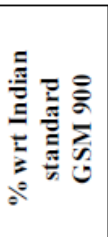 } & \multirow[b]{2}{*}{ 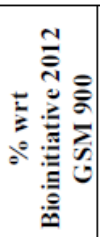 } & \multirow[b]{2}{*}{ 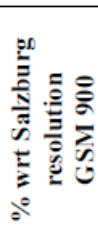 } \\
\hline & & & $\begin{array}{l}\text { GSM-900 } \\
\left(\mathrm{mW} / \mathrm{m}^{2}\right)\end{array}$ & $\begin{array}{c}\text { GSM-1800 } \\
\left(\mathrm{mWV} / \mathrm{m}^{2}\right)\end{array}$ & & & & & & \\
\hline 1 & Lawipu & 11 & 0.0088 & 0.0754 & 0.042 & 1 & 0.00018 & 0.0019 & 1.76 & 8.8 \\
\hline 2 & Darlawn & 14 & 0.114 & 0.080 & 0.097 & 13 & 0.0023 & 0.0251 & 23 & 11.4 \\
\hline 3 & Seling & 12 & 0.180 & 0.070 & 0.125 & 20 & 0.0036 & 0.0396 & 36 & 18 \\
\hline 4 & Saitual & 12 & 0.460 & 0.230 & 0.345 & 20 & 0.0036 & 0.0396 & 36 & 18 \\
\hline 5 & Tlungvel & 12 & 0.220 & 1.170 & 0.695 & 25 & 0.0044 & 0.0484 & 44 & 22 \\
\hline 6 & Durtlang & 13 & 0.670 & 1.300 & 0.985 & 76 & 0.0134 & 0.1474 & 134 & 67 \\
\hline 7 & Kulikawn & 11 & 0.370 & 2.690 & 1.530 & 42 & 0.0074 & 0.0814 & 74 & 37 \\
\hline 8 & Chawlhhmun & 12 & 1.160 & 1.930 & 1.545 & 131 & 0.0232 & 0.2552 & 232 & 116 \\
\hline 9 & K. Vengthlang & 12 & 2.500 & 1.790 & 2.145 & 284 & 0.0500 & 0.5500 & 500 & 250 \\
\hline 10 & A.Veng & 13 & 2.200 & 4.170 & 3.185 & 250 & 0.0440 & 0.4840 & 440 & 220 \\
\hline 11 & Tanhril & 12 & 1.960 & 5.480 & 3.720 & 222 & 0.0338 & 0.4312 & 392 & 196 \\
\hline 12 & Chanmari & 12 & 6.780 & 2.270 & 4.525 & 770 & 0.1356 & 1.4916 & 1356 & 678 \\
\hline 13 & Zemabawk & 21 & 2.000 & 7.860 & 4.93 & 227 & 0.0400 & 0.4400 & 400 & 200 \\
\hline 14 & M.Vengthlang & 17 & 3.500 & 7.810 & 5.655 & 398 & 0.0700 & 0.7700 & 700 & 350 \\
\hline 15 & Maubawk & 12 & 10.50 & 7.35 & 8.92 & 1193 & 0.2234 & 2.333 & 2100 & 1050 \\
\hline 16 & Ramhlun N & 13 & 3.500 & 14.67 & 9.085 & 398 & 0.07 & 0.7700 & 700 & 3500 \\
\hline 17 & B.Vengthlang & 12 & 3.310 & 20.80 & 12.05 & 376 & 0.0662 & 0.7282 & 662 & 331 \\
\hline 18 & C.Veng & 12 & 6.82 & 30.95 & 18.88 & 775 & 0.1362 & 1.500 & 1364 & 682 \\
\hline
\end{tabular}

\subsection{Power Density versus Health Complaints}

Average value of the measured power density from each locality was compared with the number of significant health complaints on comparison with Lawipu where power density was very low. It has been observed that significant health complaints starts to occur only when average power density is more than $2.145 \mathrm{~mW} / \mathrm{m}^{2}$. No significant complaint was found in the localities where the average power densities were less than $2.145 \mathrm{~mW} / \mathrm{m}^{2}$.

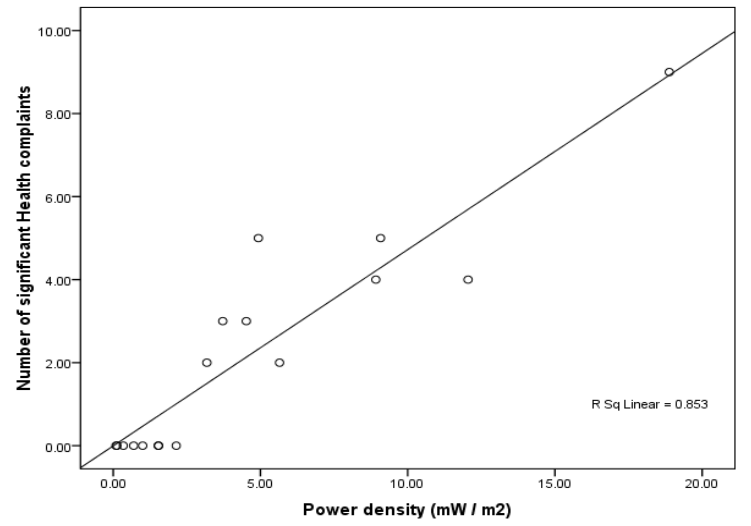

Fig. 1. Correlation graph for responses on health complaints vs power density for comparison of Lawipu with other localities.

At the same time, the number of significant health complaints on comparison between responses of male and female from each locality was compared with power density of the locality. It has been observed that significant health complaints start to occur only when average power density is more than $3.185 \mathrm{~mW} / \mathrm{m}^{2}$. Below this value of power density significant health complaint was not observe.

Correlation graphs for Power density versus significant health complaints are plotted in figures $1 \& 2$. For 
comparison of Lawipu and other localities strong positive correlation of $\mathrm{R}^{2}$ value of 0.853 was obtained, and for male - female comparison positive correlation of $\mathrm{R}^{2}$ value of 0.705 was obtained.

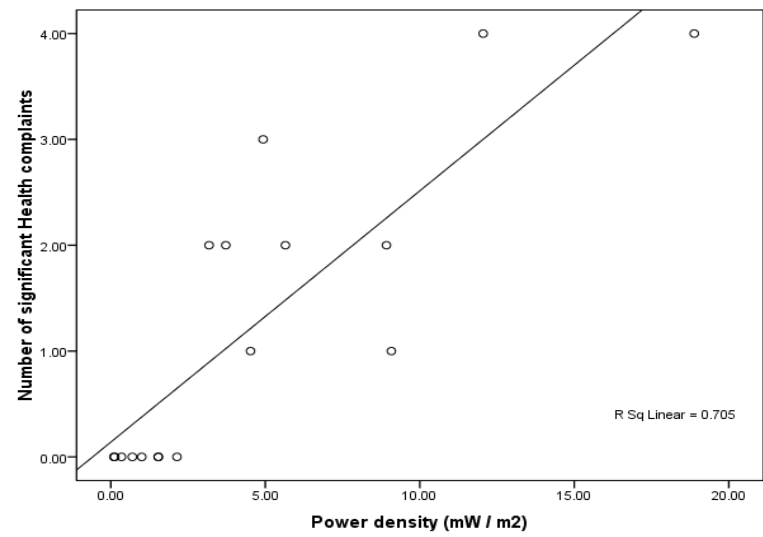

Fig. 2. Correlation graph for responses on health complaints vs power density for comparison of Male vs female.

\section{Conclusion}

It has been observed that all the measured values of power density in all the 18 localities were lower than the safety limit recommendation of ICNIRP and the department of Telecommunications, Govt. of India. However, in 14 different localities (all in Aizawl city) the average values of the measured power densities were higher than the recommendations of Bioinitiative report 2012, Salzburg resolution 2000 and EU (2001). Although the measured power densities were very low compares to the recommendations of ICNIRP and the current Indian standard, it has been observed that many inhabitants were still having complaints on the non specific health symptoms since the erection of the tower.

From the comparisons of health complaints of male and female from each locality, it was observed that females were having more complaints than male. The most common complaint was muscle pain. However, there are many other factors which could contribute to the health complaints other than RF/MW radiation. It is not wise to conclude that all the observed health complaints were due to the radiation alone. However, it has been observed that more is power density, more is health complaints.

\section{References}

[1] Bletter, M., Schlehofer, B., Breckenkamp, J., Kowall, B., Schmiedel, S., Reis, U., et al. (2009). Mobile phone base stations and adverse effects: Phase 1 of a population-based, cross-sectional study in Germany. Occup Environ Med., 66, 118-23.

[2] U.S. Food and Drug Administration (FDA). (2009). Radiation emitting Products: Reducing Exposure: Hands-Free Kits and Other Accessories. Retrieved from http://www.fda.gov/Radiation-Emitting Products/Radiation Emitting Products and procedures/ Home Business and Entertainment/ Cell Phones/ucm116338.htm

[3] Roosli, M., Moser, M., Baldinini, Y., Meier, M., \& Braun-Farhlander, C. (2004). Symptoms of ill-health ascribed to electromagnetic field exposure-a questionnaire survey. Int J Hyg Environ Health, 207, 141-50.

[4] Leitgeb, N., \& Schrottner, J. (2003). Electrosensibility and electromagnetic hypersensitivity. Bioelectromagnetics, 24, 387-94.

[5] Roosli, M. (2008). Radiofrequency electromagnetic field exposure and non specific health symptoms of 
ill health: a systematic review. Environ Res., 107, 277-287.

[6] Ahlbom, A., Green, A., et al. (2004). Epidemiology of health effects of radiofrequency exposure. Environmental Health Perspective, 112(17), 1741-1754.

[7] Neubauer, G., Feychting, M., Hamnerius, Y., Kheifets, L., Kuster, N., Ruis, I., et al. (2007). Feasibility of future epidemiological studies on possible health effects of mobile phone base stations. Bioelectromagnetics, 28, 224-230.

[8] Frei, P., Mohler, E., Neubauer, G., Theis, G, Burgi, A, Frohlich, J., et al. (2009). Temporal and spatial variability of personal exposure to radio frequency electromagnetic fields. Environ Res., 109, 779-785.

[9] Valberg, P. A., Deventer, T. E., \& Repacholi, M. H. (2007). Workgroup report: base stations and wireless networks-radiofrequency (RF) exposures and health consequences. Environ Health Perspect, 115, 416-424.

[10] Zwarmborn, A., Vossen, S., Leersum, B., Ouwens, M., \& Makel, W. (2003). Effects of global communication system radio-frequency fields on well being and cognitive functions of human subjects with and without subjective complaints: TNO-report FEL-03-C148. The Hague: THO Physics and Electronic Laboratory.

[11] Martinez-Gonzalez, A. M., \& Fernandez-Pascual, A. (2002). Practical procedure for verification of compliance of digital mobile radio base stations to limitations of exposure of the general public to electromagnetic fields. IEEE Proceedings on Microwaves, Antennas and Propagation (USA), 149, 218-228.

[12] World Health Organisation (WHO). (2011). Media centre, electromagnetic fields and public health: Mobile phones. Retrieved from http://www.who.int/mediacentre/factsheets/fs193/en/

[13] Chia, S. E., Chia, H. P., \& Tan, J. S. (2000). Prevalence of headache among handheld cellular telephone users in Singapore: A community study. Environmental Health Perspectives, 108(11), 1059-1062.

[14] International Agency for Research on Cancer. Retrieved from www.iarc.fr/en/media-centre/pr/2011/pdfs/pr208_E.pdf

[15] Santini, R., et al. (2002). Study of the Health of People living in the vicinity of mobile phone base stations: I. Influences of distance and sex. Pathol Biol., 50, 369-373.

[16] Muoaaz, N., \& Mohammed, T. S. (2011). Safety measurements of electromagnetic fields radiated form mobile base stations in the western region of Saudi Arabia. Wireless Engineering Technology, 2, 221-229.

[17] Cindy, S., \& David, O. C. (2012). Key Scientific Evidence and Public Health Recommendations. Retrieved from www.bioinitiative.org

[18] Haumann, T., Munzenberg, U., et al. HF Radiation levels of GSM Cellular Phone Towers in Residential Areas. Retrieved from hbelc.org/pdf/memdocs/cellularphoneradiation.pdf

[19] Department of Telecommunications, Govt. of India. (2013). Advisory Guidelines for State Governments for Issue of Clearance for Installation of Mobile Towers. Retrieved from http://www.dot.gov.in/access-services/journey-emf

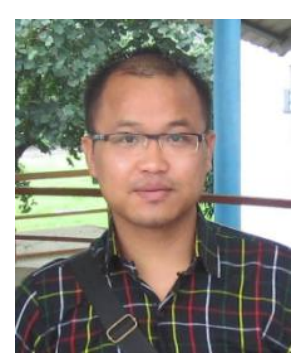

Lalrinthara Pachuau was born in June 23, 1983 in Aizawl city, the capital city of Mizoram state in India. He obtained the MSc (physics) from Indian Institute of Technology, Guwahati in 2007. He had qualified in National Eligibility Test (NET/JRF) conducted by UGC-CSIR in December 2006 and Graduate Aptitute Test in Engineering (GATE) conducted by MHRD in February 2007. His major field of interest is in Electromagnetic waves and their possible health effects and in General Relativity.

He was selected as fellow, CPYLS (CSIR Programme for Young Leadership in Science) 
in the year 1999 - 2000 and had visited CSIR Laboratories (Jorhat-1999, Delhi-2000) during these years. He joined his current job as ASSISTANT PROFESSOR, in the Department of Physics, Pachhunga University College, Aizawl, Mizoram, India in February 2008. He started research career since 2012 and had published eight (8) research papers in different International and Indian Journals. He had co-authored one book 'Practical Manual' for BSc students, which was published by the college. He had written more than sixty (60) different popular science articles for laymen and High school students mostly in Mizoram Science Journal. Currently he is doing research in the field of RF/MW Radiation and their possible harmful effects on Human. $\mathrm{He}$ is about to submit his $\mathrm{PhD}$ thesis in Mizoram University.

Mr. Pachuau is member of STAM (Science Teachers' Association Mizoram) and is holding the Joint Secretary position. He is also member of MAS (Mizo Academy of Sciences), MSS (Mizoram Science Society), Secretary, Mizoram Amateur Astronomy Club. He is currently holding the post of Editor OF Mizoram Science Journal (monthly Journal). He had been awarded Mizoram Science Journal's Best article Award four times (2000, 2002, 2003, 2013), Best contribution Award three times (2010, 2011, 2012). 